特別講演 I

\title{
Factors Affecting the Clinical Significance of Red Cell Antibodies
}

\author{
George Garratty, PhD, FIMLS, MRCPath. \\ Scientific Director \\ American Red Cross Blood Services \\ Los Angeles-Orange Counties Region \\ 1130 South Vermont Avenue \\ Los Angeles, CA 90006 \\ USA \\ and \\ Clinical Professor of Pathology \\ University of California, Los Angeles

\section{Mechanisms of Red Cell Destruction}

Red blood cells (RBCs) may be destroyed intravascularly through a complement-mediated mechanism, or extravascularly through interaction of $\mathrm{RBC}$-bound $\mathrm{IgG}$ and/or complement with macrophages within the reticuloendothelial system $(\mathrm{RES})^{1,2)}$. We have learned a great deal about intravascular complementmediated RBC destruction because we have learned much about complement activation over the last 30 years $^{1-3)}$. Many allo and auto RBC antibodies can activate complement but few can do it efficiently enough for the complement activation to go to completion to yield membrane defects and subsequent lysis of the cell. Far more commonly RBCs coated with complement, and/or IgG, are removed extravascularly by macrophages, especially in the spleen and liver. RBCs coated with IgG and/or complement can adhere to specific receptors on macrophages and several events can occur. The RBCs can be totally phagocytosed or partially phagocytosed. When part of the $\mathrm{RBC}$ is phagocytosed, the part that escapes is often spherocytic, thus spherocytosis is often observed on peripheral blood smears of patients with immune extravascular RBC destruction. Sometimes the RBC is not phagocytosed but is damaged. The RBC may be totally hemolyzed by antibody dependent cell-mediated cytotoxicity (ADCC), or the membrane may be damaged; the RBCs may escape from the macrophage but have a shortened RBC survival'4).

Normal RBCs are known to have IgG and complement on their surface. Several investigators have reported that normal $\mathrm{RBCs}$, with a negative direct antiglobulin test (DAT) have 5-90 (with a mean of $30-40)$ IgG molecules/RBC ${ }^{5,6}$. There is a bigger variation with the number of complement molecules/RBC reported, various workers have reported $50-560 \mathrm{C} 3 \mathrm{~d}$ molecules/RBCs; this probably reflects the variation in the antiglobulin sera (anti-C3d) used.

\section{Factors Influencing the Clinical Significance of RBC Antibodies}

Table 1 shows the major factors that influence whether an antibody will be clinically significant or insignificant.

\section{Characteristics of Antibody}

Class and Subclass

$\mathrm{RBC}$ auto and alloantibodies can belong to the IgA, IgG (all four subclasses) or IgM class. Only IgG and IgM antibody can activate complement. IgG3 is the most efficient at activating complement, followed by IgG1; IgG2 is poor at activating complement, and IgG4 rarely does. Macrophages were initially said to have receptors for IgG1 and IgG3 (Fc receptor) and some complement components (the CR1 and CR3 receptors).

Theoretically, from the above information, one would expect that IgG1, IgG3 and IgM antibodies should have the potential to be clinically significant, but IgA, IgG2 and IgG4 should not be clinically significant. This is usually true but exceptions do occur. For instance, there are several reports in the 
Table 1 Factors that Influence the Clinical

Significance of RBC Antibodies

1. Characteristics of Antibody
a. Class
b. Subclass
c. Specificity
d. Thermal range
e. Complement activating efficiency
f. Affinity

2. Quantity of RBC-bound IgG/Complement

3. Characteristics of Target Antigen

a. Quantity of antigen on membrane

b. Distribution of antigen on membrane

c. Antigen in tissues and/or body fluids

4. Type of Complement Present on $\mathrm{RBC}_{\mathrm{S}}$

5. Activity of Reticuloendothelial System

Table 2 Heterogeneity of Human ( $\mathrm{Hu})$ Macrophage Fc Receptors

\begin{tabular}{l|c|c|c|c}
\hline \multirow{2}{*}{ Receptor } & \multicolumn{4}{|c}{ Affinity for } \\
\cline { 2 - 5 } & IgG1 & IgG2 & IgG3 & IgG4 \\
\hline HuFc vRI & high & 0 & high & low \\
HuFc vRII & high & low & high & low \\
HuFc vRIII & high & 0 & high & 0 \\
\hline
\end{tabular}

literature of "warm type" autoimmune hemolytic anemia (AIHA) associated with IgA autoantibodies"). We have also reported two cases of AIHA associated with IgG2 autoantibodies ${ }^{7)}$, and a very unusual case of hemolytic disease of the newborn associated with an IgG2 anti-Jk ${ }^{\text {b8) }}$. These cases may be explained by the recent findings that suggests that the reason for IgG2 and IgG4 not reacting with macrophages is not that macrophages completely lack receptors for these proteins, but rather that there is an affinity difference between IgG1, IgG2, IgG3 and IgG4 for the Fc receptor. Table 2 shows that the Fc receptor has been shown to be quite heterogenous, being composed of at least 3 moieties termed human Fc gamma R1, R2 and R3. R1 has a high affinity for IgG1 and IgG3, does not react with IgG, and has a low affinity for IgG4. R2 has a high affinity for IgG1 and IgG3, and a low affinity for IgG2 and IgG4. R3 only reacts with IgG1 and IgG3. Thus, it is now easier to understand that on rare occasions even IgG2 and IgG4 may be clinically significant.

Earlier reports suggested that IgG3 antibodies would cause overt in vivo hemolysis but we were not able to confirm that. We have reported on normal blood donors, patients and neonates with strongly positive DATs due to IgG3 who had no obvious signs of hemolytic anemia ${ }^{9)}$. Nevertheless, it is becoming increasingly obvious that IgG3 is not only more efficient at activating complement but is more efficient in interacting with macrophages. Engelfriet's group showed that the same amount of IgG more efficiently inhibited in vitro monocyte cytotoxicity against IgG1-coated red cells than IgG3-coated red cells; suggesting, that IgG3-coated red cells would be destroyed more efficiently than IgG1-coated red cells when they were competing with free plasma IgG for macrophage $\mathrm{Fc}$ receptors ${ }^{4}$. Douglas et $\mathrm{al}^{10}{ }^{10}$ showed that they needed $500 \mathrm{IgG} 1$ molecules per red cell before they observed phagocytosis in an in vitro monocyte assay, but only $100 \mathrm{IgG} 3$ molecules per red cell were needed to give the same result. Zupanska's group in Poland has published similar findings ${ }^{11}$.

Both Engelfriet's) and Zupanska's ${ }^{12)}$ groups have also made the important observations that red cells that are sensitized with an amount of IgG3, below the threshold of the direct antiglobulin test, can interact with monocytes in vitro, in contrast to RBCs sensitized with similar amounts of IgG1, where no reactions occurred. These findings could be very important in trying to explain the so-called "Coombs Negative" AIHA, and perhaps hemolytic trnasfusion reactions with no detectable antibodies.

\section{Specificity, Thermal Range and Complement Activating Ability of RBC Antibody}

The association of certain blood group specificities with potential clinical significance is closely related to the thermal range of the antibody, its ability to activate complement, and the characteristics of its respective antigen; especially, the number of antigenic sites, and whether there is competition with antigen on other cells or body fluids. Sometimes all these factors, and at other times only one of these factors, may explain why the antibody is not pathogenic. The best example of this is the thermal range. Alloantibodies 
Table 3 Complement Activating Efficiency of RBC Antibodies Does Antibody Cause :

\begin{tabular}{l|l|l|l}
\hline Specificity & $\begin{array}{c}\text { In Vitro or } \\
\text { In Vivo RBC } \\
\text { Complement } \\
\text { Sensitization? }\end{array}$ & $\begin{array}{c}\text { In Vitro } \\
\text { Hemolysis? }\end{array}$ & $\begin{array}{c}\text { In Vivo } \\
\text { Complement-Mediated } \\
\text { Intravascular } \\
\text { Hemolysis? }\end{array}$ \\
\hline Anti-A, -B & Usually & Often & Usually \\
Anti-Rh & No & No & No \\
Anti-I, -i & $($ Yes)* & Rarely** & Rarely** \\
Anti-Lea & Usually & Sometimes & Rarely \\
Anti-M, -N & No & No & No \\
Anti-P1 & Sometimes & Rarely & No \\
Anti-K & Sometimes (19\%) & No & No \\
Anti-Fy & Sometimes (13\%) & No & No \\
Anti-Jk & Sometimes (46\%) & Rarely & Rarely \\
Anti-S & Sometimes (33\%) & No & No \\
Anti-Vel & Often & Sometimes & Sometimes \\
Anti-PP $P^{\mathrm{a}}$ & Often & Sometimes & Sometimes \\
\hline
\end{tabular}

* In vitro sensitization occurs commonly when conditions are optimal (e.g., low temperature, low ionic strength or with enzyme-treated $\left.\mathrm{RBC}_{\mathrm{S}}\right)$; in vivo sensitization is rare and occurs only when antibody is of high thermal amplitude $\left(30-37^{\circ} \mathrm{C}\right)$.

** Only when antibody is of high titer and thermal range.

such as anti- $\mathrm{A}_{1},-\mathrm{Le}^{\mathrm{a}},-\mathrm{Le} \mathrm{e}^{\mathrm{b}},-\mathrm{M},-\mathrm{N},-\mathrm{P}_{1}, \mathrm{I}$ usually do not react at $37^{\circ} \mathrm{C}$. When such alloantibodies do not react at $37^{\circ} \mathrm{C}$, they are never clinically significant ${ }^{13-15)}$. When they do react at $37^{\circ} \mathrm{C}$, then they have to be considered to have the potential to cause shortened $\mathrm{RBC}$ survival. If antibodies activate complement, they are generally more clinically significant, but very few activate complement efficiently enough to cause acute complement-mediated intravascular lysis. Anti-A and anti-B are, of course, the best examples of this, but on rare occasions some Kidd antibodies and some exotic antibodies such as anti-Vel cause intravascular lysis. Other than these examples it is a rare event to find an alloantibody causing intravascular lysis. It is also rare to find autoantibodies that are associated with significant intravascular lysis. This is usually found in paroxysmal cold hemoglobinuria ( $\mathrm{PCH})$, acute hemolytic anemia in children, and in a few cases of drug-induced immune hemolytic anemia ${ }^{2}$. Although it is rare to find complement activation efficient enough to cause direct lysis of red cells, it is relatively common to find complement activation and some complement components detectable on the red cells by the antiglobulin test. We have found that 46 percent of Kidd, $10-20 \%$ of Duffy and Kidd antibodies, and 33\% of S antibodies, cause complement sensitization of RBCs, and $80 \%$ of AIHAs have complement on their red cells (see Table 3 and references 2, 3).

Complement may enhance the efficiency of the interaction of IgG-coated RBCs with macrophages. Mollison et al ${ }^{13)}$ show a good example on page 553 of their book. RBCs were sensitized with similar amounts of a complement-binding IgG anti-Fy and a noncomplement-binding IgG anti-D, and labeled with ${ }^{51} \mathrm{Cr}$. The extravascular destruction of the RBCs coated with IgG $\left(7.7 \mu \mathrm{g} / \mathrm{ml}\right.$ anti-Fy $\left.{ }^{\mathrm{a}}\right)$ and complement was much faster than those coated with only $\operatorname{IgG}(9.3 \mu \mathrm{g} / \mathrm{ml}$ of anti-D).

\section{Affinity of Antibody}

An antibody characteristic that is sadly underinvestigated, in terms of its influence on clinical significance, is affinity. There are very little data proving its influence. The best data are from the 1960's. Schwartz and Costea studied 3 examples of anti-D, with different affinities for D+ red cells ${ }^{16}$. They sensitized red cells with 3 anti-D and measured the time it took for $50 \%$ of the anti-D to spontaneously elute from the red cells, when left at 37 degrees. The in vitro elution times, or ET, reflected the affinity of the anti-Ds and were $40 \mathrm{mins}, 100 \mathrm{mins}$ and $160 \mathrm{mins}$. Thus, the shortest elution time ( $40 \mathrm{mins}$ ) would equate with the antibody with the lowest affinity, and the longest elution time (160 mins) with the highest affinity. Red cells were then sensitized with the 3 anti-D and labelld with ${ }^{51} \mathrm{Cr}$. Red cell survival studies 
were performed. The red cells sensitized with the antibody that had the longer elution time ( 160 mins), or the highest affinity, were destroyed faster than the red cells sensitized with the antibody with the shortest ET (40 mins) or lower affinity. This strongly suggests that antibody affinity may be an important factor in determining the pathogenicity of alloantibodies.

Schwartz and Costea also performed one of the only experiments I know relating affinity of autoantibody to the degree of red cell destruction ${ }^{16)}$. They sensitized red cells in vitro with similar quantities of autoantibody in a patient's serum, and in an eluate prepared from the patient's red cells. The sensitized red cells were then labeled with ${ }^{51} \mathrm{Cr}$ and their in vivo survival followed. The red cells sensitized in vitro with antibody in the eluate were destroyed faster than red cells sensitized with the serum antibody. It was assumed that higher affinity antibodies would be adsorbed onto a patient's red cells in vivo leaving lower affinity antibodies in the serum, and thus red cells sensitized in vitro with antibody in the eluate would be sensitized with the higher affinity antibody, causing their increased destruction.

These results would appear to be in direct contrast, with some patients, with warm type autoimmune hemolytic anemia, that we have investigated, who appeared to have low affinity IgG autoantibodies and severe hemolytic anemia ${ }^{17)}$. These low affinity antibodies were defined by the fact that they were often lost from red cells during the in vitro washing phase, especially when the red cells were washed at $37^{\circ} \mathrm{C}$. We encountered 22 patients with AIHA associated with low affinity autoantibodies that we encountered in a 10 year period. Seventeen were sent to us as "Coombs Negative" AIHA. But we found 11 were DAT+ in our lab; 8 were DAT negative when the red cells were washed in $37^{\circ} \mathrm{C}$ saline. All of the patients had strongly positive DATs when their red cells were washed with ice-cold saline or with low ionic strength solution. Appropriate controls were used to exclude false positive results due to cold autoagglutinins. Thus, patients with severe AIHA can present sometimes with negative direct antiglobulin tests because we wash off low affinity antibody during the washing phase of the antiglobulin test. Although this finding of severe hemolytic anemia associated with low affinity autoantibodies seems not to agree with Schwartz and Costea's findings ${ }^{16)}$, it perhaps does. There is a possibility that the marked in vivo hemolysis in these patients was caused by high affinity antibodies and that all, or most, of the red cells sensitized with such antibodies had been removed from the circulation, and we were only detecting low affinity antibodies left on the surviving red cells. This is a good example of why we should not always expect our in vitro results to correlate with the in vivo findings. It is possible that the same rationale might explain some cases of "Coombs Negative" AIHA and hemolytic transfusion reactions with no detectable antibody.

\section{Quantity of RBC-Bound IgG and Complement}

One of the major questions regarding relative clinical significance is whether differences can be totally explained on a quantitative basis. It is accepted that if one studies a single antibody, then there is a direct relationship between the amount of antibody on the red cell and extravascular destruction. Mollison et al ${ }^{13)}$ sensitized RBCs in vitro with increasing amounts (1.6 to 43 micrograms of antibody) of a single $\mathrm{Rh}$ antibody and ${ }^{51} \mathrm{Cr}$ red cell survivals were performed. As might be expected, as the amount of red cell-bound IgG increased, survival decreased. On the other hand, we also know that if we try to compare different antibodies, even of the same specificity, this nice relationship doesn't always exist. This is especially true when one examines IgG autoantibodies and it is obvious that quantity is not always the answer. We see examples of severe autoimmune hemolytic anemia associated with weak IgG sensitization, and many examples of red cells strongly sensitized with IgG autoantibodies that appear to be surviving normally.

The work on methyldopa produced several fascinating facts, one of which was that although $15 \%$ of the patients taking methyldopa develop positive DATs, and although these may be $4+$, representing thousands of red cell-bound IgG molecules, less than $1 \%$ of these patients show any sign of hemolytic anemia. Most of these antibodies are IgG1, so why don't they react efficiently with macrophage Fc receptors? van der Meulen et $\mathrm{al}^{18)}$ suggested that there was a quantitative hemolytic threshold for IgG1 antibodies and they could detect this by using flow cytometry. In other words, two patients might have 4+ DATs but only one patient may have sufficient IgG molecules on the red cells to trigger efficient interaction with macrophages. In fact the Dutch workers suggested that this totally explained the differences between 
methyldopa-induced positive DAT hemolyzers and nonhemolyzers. This seemed to us, at the time, an acceptable hypothesis as we knew that the number of IgG molecules per red cell could vary considerably within the 4+ DAT group.

Hughes-Jones et al $^{19)}$ had shown some years previously that, within the $4+$ antiglobulin group, antigen site saturation with IgG antibody could vary from $30 \%$ to theoretically $100 \%$. We also know, that once you get more than $1000 \mathrm{IgG}$ molecules per red cell you obtain a $4+$ antiglobulin test ${ }^{2}$. Thus, a $4+$ antiglobulin test, due to anti-Rh, can vary from having 1,000-30,000 IgG molecules per red cell. One might expect the macrophages to react differently to red cells coated with such different amounts of IgG1 antibody. When we got our flow cytometer in Los Angeles, one of the first things we did was to try to confirm the findings of the Dutch group.

We presented some of our findings at the American Socity of Hematology in $1984^{20)}$, and published them in Transfusion in $1990^{21}$. We quickly found, and agreed, that flow cytometric quantitative analysis was superior to the antiglobulin test in differentiating quantitative differences within the 4+ DAT group. Table 4 shows that red cells sensitized with different dilutions of anti-D could not be differentiated by the antiglobulin test. All cells reacted $4+$ and all cells gave similar agglutination scores when tested against dilutions of antiglobulin sera. Flow cytometry differentiated them easily, showing less fluorescence per cell as the amount of anti-D decreased.

$\mathrm{We}^{22)}$ studied a larger number of DAT+ subjects than van der Meulen, who studied 29 cases $^{19)}$. We studied 73 DAT positive subjects; 10 of the positive DATs were idiopathic, or of unknown causes; 25 were due to methyldopa and 38 were neonates born to mothers with antibodies of potential clinical significance. Twenty-eight patients had hemolytic anemia and 45 did not $^{22)}$. Table 5 shows the results of our studies measuring the relative amount of red cell-bound IgG, expressed as fluorescence per red cell, in 3 groups of DAT+ patients; Idiopathic, Methyldopa-induced and Neonates born to mothers with Rh antibodies; each group is divided into those with hemolytic anemia and those without. We found that the mean amount of cell-bound IgG was always more in the patients with hemolytic anemia than those without in all groups; but when we studied the range of results we found overlap, between hemolyzers and nonhemolyzers in all groups, such that we could not determine a definite quantitative hemolytic threshold for individual patients, even using flow cytometry. We concluded that although the quantity of cell-bound IgG is a significant factor in determining the degree of red cell destruction, it does not explain all of the anomalies we see, particularly within the common group of patients with IgG1 autoantibodies.

A fascinating group of patients are at the other end of the spectrum, that is to say patients with very little, if any, detectable antibody, yet who have what appears to be an immune hemolytic anemia. Gilliland explained these Coombs negative autoimmune hemolytic anemias on a quantitative basis ${ }^{23}$. The red cells of such patients were said to have enough red cell-bound IgG to react with macrophages in vivo but not be detected by the antiglobulin test. Over the years I have become increasingly doubtful about this

Table 4 Comparison of Antiglobulin Test and Flow Cytometric Analysis of $\mathrm{RBC}_{\mathrm{S}}$ Strongly Sensitized with IgG Anti-D (21)

\begin{tabular}{c|c|c}
\hline $\begin{array}{c}\text { Anti-D } \\
\text { dilution }\end{array}$ & $\begin{array}{c}\text { Indirect } \\
\text { antiglobulin test }\end{array}$ & $\begin{array}{c}\text { Flow } \\
\text { cytometry* }\end{array}$ \\
\hline $1: 40$ & $4+(65)$ & 84.7 \\
$1: 20$ & $4+(62)$ & 130.7 \\
$1: 10$ & $4+(68)$ & 183.2 \\
$1: 5$ & $4+(68)$ & 212.0 \\
\hline
\end{tabular}

* Values in parentheses are titration scores. Mean amount of fluorescence per RBC (on an arbitrary scale $0-255$ ).
Table 5 Relationship of Relative Quantity of RBCBound IgG (Measured by Flow Cytometry) to Clinical Significance (21)

\begin{tabular}{l|c|c|c}
\hline \multirow{2}{*}{ DAT + Patients } & \multirow{2}{*}{$\begin{array}{c}\text { Hemolytic } \\
\text { anemia (n) }\end{array}$} & \multicolumn{2}{|c}{ Fluorescence per RBC } \\
\cline { 3 - 4 } & & mean & range \\
\hline Idiopathic & yes ( 7) & 99 & $32-255$ \\
Methyldopa & no ( 3) & 35 & $32-41$ \\
& yes ( 8) & 57 & $28-127$ \\
Neonates & no (17) & 40 & $30-53$ \\
& no (13) & 63 & $30-205$ \\
& yes (25) & 33 & $27-45$ \\
\hline
\end{tabular}


quantitative hypothesis.

When we measured RBC-bound IgG by Gilliland's complement fixation antiglobulin consumption assay (CFAC) we confirmed that one needs to have about $200 \mathrm{IgG}$ molecules per RBC before seeing macroscopic agglutination by the antiglobulin test ${ }^{2}$. But when Dr. Petz and myself used the Gilliland CFAC, in the 1970's, to diagnose "Coombs" negative autoimmune hemolytic anemia we found that almost $40 \%$ of the patients had more than $200 \mathrm{IgG}$ molecules per red cell ${ }^{2}$.

For the last 12 years we have used a direct enzyme-linked antiglobulin test, or ELAT, instead of the CFAC assay, to diagnose these patients. Although we no longer express our results as molecules per red cell, some of our results parallel the anomalies seen with the Gilliland assay ${ }^{24}$. Results of quantitative assays do not completely support Gilliland's quantitative theory ${ }^{23,24)}$. As mentioned previously, Engelfriet's and Zupanska's groups showed that monocytes would react with red cells sensitized with amounts of IgG3 (but not IgG1) that were not detectable by the antiglobulin test ${ }^{4,12}$. Thus, it is possible that both quantity and quality (e.g., IgG subclass) may play a role.

\section{Characteristics of Target Antigen}

The quantity and distribution of antigenic sites on the RBC membrane obviously influences the quantity of antibody on the RBC, which has been discussed previously, and the ability of the antibody to activate complement. When antigen is present on cells (e.g., in tissue) other than RBCs and/or present in body fluids (e.g., plasma), it can compete with RBC antigen, thus limiting an antibody in its clinical significance. This is discussed in detail elseqhere ${ }^{13)}$, and will not be discussed here.

\section{Type of Complement on RBC Membrane}

When the first component of complement is activated, the red cell usually becomes sensitized with $\mathrm{C} 4 \mathrm{~b}$, and often the system is efficient enough for cleavage of $\mathrm{C} 3$ to occur leading to red cell-bound C3b. When blood group antibodies are considered, even those capable of activating complement, are usually not efficient enough to activate the final three steps, where $\mathrm{C} 5$ is cleaved, and the membrane attack complex is present on the membrane, leading to direct lysis of the cell. Thus, the major question is: How well do red cells survive in vivo once they become coated with $\mathrm{C} 3$ ? To answer this we need to relate to the breakdown products of $\mathrm{C} 3$ that are formed in vivo.

C3 is first cleaved by C3 convertase to generate a small molecule, C3a anaphylatoxin, and the larger $\mathrm{C} 3 \mathrm{~b}$ that attaches to the red cell membrane. At this stage the red cell can interact with the complement receptors on macrophages and be phagocytosed, or damaged by cytotoxicity. This interaction is quite inefficient as C3b is cleaved very rapidly by factor I (previously known as C3 inactivator), and its cofactors $\mathrm{H}$ and the macrophage CRI receptor, forming a cell-bound molecule known as $\mathrm{iC} 3 \mathrm{~b}$ (or iC3bi), and releasing a small fragment C3f. As the CR1 and CR3 receptors of macrophages interact with iC3b, the cell is still susceptible to damage at this stage. The iC $3 \mathrm{~b}$ molecule is also cleaved by Factor I, releasing a large part of the molecule, C3c, from the cell, leaving a molecule known as C3d,g on the cell. This appears to be the final cell-bound product in vivo. In vitro, the C3d,g molecule can be cleaved by trypsin leaving only C3d on the red cell, releasing $\mathrm{C} 3 \mathrm{c}$ and $\mathrm{C} 3 \mathrm{~g}$ into the fluid phase $\mathrm{e}^{24)}$.

Macrophages have 2 complement receptors, that are involved in red cell destruction, CR1 and CR3-CR1 reacts with $\mathrm{iC} 3 \mathrm{~b}$ and $\mathrm{C} 3 \mathrm{~b}$. CR3 reacts with only $\mathrm{iCb} 3$. Thus, whenever a red cell antibody activates complement in vivo and the red cell becomes coated with $\mathrm{C} 3 \mathrm{~b}$ the following events occur. As the red cells pass through the $\mathrm{RES}$, the $\mathrm{C} 3 \mathrm{~b}$-coated red cells may attach to $\mathrm{CR} 1$ receptors on macrophages, some cells may be immediately phagocytosed but the $\mathrm{C} 3 \mathrm{~b}$ on many of these cells will be cleaved into iC $3 \mathrm{~b}$ by Factor I, and cofactors $\mathrm{H}$ and the CR1 receptor. The iC3b-coated red cells may also interact with the CR1 and CR3 macrophage receptors, leading to a further population of red cells being phagocytosed. Many of the iC $3 \mathrm{~b}$ coated cells will be acted on by Factor I and will be cleaved to C3d,g. As macrophages have no, or very inefficient receptors for C3d,g these cells may circulate and survive relatively normally, even though the DAT on such cells may be strongly positive. Thus, to summarize: complement activation may cause acute intravascular lysis; sequestration of the red cells in the reticuloendothelial system, especially in the liver; temporary sequestration with release of cells with normal or perhaps shortened survival; or, even cells 
with normal survival.

\section{Activity of Reticuloendothelial System (RES)}

Most of the studies relating to factors influencing clinical significance have emphasized properties of the $\mathrm{RBC}$ antigens or antibodies, but another important factor to explain findings in an individual patient is the activity of their macrophages or RES. Macrophages in the RES may be less active or more active than normal and this may explain why antibodies with similar in vitro characteristics sometimes appear to vary in their clinical significance.

Perhaps the most relevant example of this effect is the experiment performed by Frank and his coworkers ${ }^{25}$ when they used chromium-labelet $\mathrm{Rh}$ sensitized red cells to study RES function in patients with immune complex disease, such as Systemic Lupus Erythematosus (SLE). When these RBCs, which were strongly sensitized with anti-D, were injected into healthy controls they were destroyed quite rapidly with a ${ }^{51} \mathrm{Cr} \mathrm{T} 1 / 2$ of less than $1 \mathrm{hr}$. But when injected into patients with SLE, there was a tremendous variation; in some patients these strongly sensitized red cells survived 10-30 times longer than in the controls. It should be pointed out that the red cells used in these studies had a 4+DAT and one could guess that weaker sensitized RBCs may have survived relatively normally under similar conditions. Frnak et al $\left.{ }^{25}\right)$ suggested that this was due to blockade of the macrophage Fc receptors by preformed DNA-anti-DNA immune complexes, thus preventing interaction with the $\mathrm{Rh}$ coated red cells.

From our point of view it means that in one particular patient a particular antibody might cause severe red cell destruction, and an antibody with identical characteristics, may cause little or no destruction in another patient, because of impaired macrophage function.

Kelton has suggested that this might explain why some patients with positive DATs due to methyldopa hemolyze and others do not ${ }^{26}$. He suggested that methyldopa impairs the function of macrophages so that most patients taking the drug do not destroy the IgG coated red cells. The few patients who have a hemolytic anemia are the ones whose macrophages still retain some efficiency. He injected ${ }^{51} \mathrm{Cr}$-labeled $\mathrm{Rh}$ sensitized red cells into 9 patients taking methyldopa and 12 healthy controls. In 4 DAT positive and 3 DAT negative patients taking methyldopa, but with no hemolytic anemia, the Rh sensitized $\mathrm{RBC}$ s survived better than in normal controls. In one DAT negative patient the RBCs survived the same as in normal controls. The Rh sensitized RBCs were destroyed faster in one patient taking methyldopa who had a DAT positive hemolytic anemia. Using the same rationale as Frank et $\mathrm{al}^{25)}$ used in his experiments on immune complex disease, we could assume that the minimal red cell destruction in 7 of the cases with no hemolytic anemia, those with better red cell survival than the normal controls, could be due to depressed RES function. One DAT negative patient with no hemolytic anemia appeared to have normal RES function. In the one DAT positive patient with AIHA, Rh sensitized cells were destroyed more rapidly than in the controls, thus RES function appeared to be enhanced compared to the normal controls. These are very provocative findings and I had hoped other workers would attempt to reproduce them, including more cases of methyldopa-induced hemolytic anemia, but as methyldopa is used so rarely now the experiments will probably never be performed.

A great deal of emphasis is placed on depressed RES activity but we must not forget that the macrophages in the RES can also be hyperactive. Thus, a certain antibody may cause minimal or not red cell destruction in one patient with normal RES activity and marked destruction in another patient with enhanced RES activity. Enhanced macrophage activity has been described in infection, malignancy and inflammatory conditions. This is particularly pertinent when we address the question of why a weak antibody appears to be causing so much red cell destruction in a particular patient. It is also a factor that has been understudied in the investigation of "Coombs negative" AIHA and hemolytic transfusion reactions with no detectable antibodies.

\section{References}

1) Garratty G: Basic mechanisms of in vivo cell destruction. In: Bell CA, ed. A seminar on immune-mediated cell destruction. Washington, D.C.: American Association of Blood Banks, 1981; 1-28. 
2) Petz LD, Garratty G: Acquired immune hemolytic anemias. New York: Churchill Livingstone, 1980.

3) Garratty G: The significance of complement in immunohematology. CRC Crit Rev Clin Lab Sci 1984; 20: 25-56.

4) Engelfriet CP, von dem Borne AEG Kr, Beckers D et al: Immune destruction of red cells. In: Bell CA, ed. A seminar on immune-mediated cell destruction. Washington, D.C.: American Association of Blood Banks, 1981; 93-130.

5) Merry AH, Thomson EE, Rawlinson VI, Stratton F: A quantitative antiglobulin test for IgG for use in blood transfusion serology. Clin Lab Haematol 1982; 4: 393-402.

6) Jeje MO, Blajchman MA, Steeves K, Horsewood P, Kelton JG: Quantitation of red cell-associated IgG using an immunoradiometric assay. Transfusion 1984; $24: 473-6$.

7) Nance S, Bourdo O, Garratty G: IgG2 red cell sensitization associated with autoimmune hemolytic anemia. Transfusion 1983; 23: 413 (abstract).

8) Nance S, Arndt P, Nelson J, Garratty G: Correlation of IgG subclass with the severity of hemolytic disease of the newborn. Transfusion 1989; 29: 485 (Suppl) (abstract).

9) Nance S, Garratty G: Subclass of IgG on red cells of donors and patients with positive direct antiglobulin tests. Transfusion 1983; 23: 413 (abstract).

10) Douglas R, Rowthorne NV, Schneider JV: Some quantitative aspects of human monocyte erythropagocytosis and rosette assays. Transfusion 1985; 25: 535-9.

11) Zupanska B, Thompson E, Brojer E, Merry AH: Phagocytosis of erythrocytes sensitized with known amounts of IgG1 and IgG3 anti-Rh antibodies. Vox Sang 1987; 53: 96-101.

12) Zupanska B, Brojer E, Maslanka R, Hallberg T: A comparison between Fc receptors for IgG1 and IgG3 on human monocytes and lymphocytes using anti-Rh antibodies. Vox Sang 1985; 49: 67-76.

13) Molison PL, Engelfriet CP, Contreras M: Blood transufison in clinical medicine. 8th ed. Oxford: Blackwell Scientific Publications, 1987.

14) Petz LD, Swisher SN: Clinical practice of transfusion medicine. 2nd ed. New York: Churchill Livingstone, 1989.

15) Issitt PD: Applied blood group serology, 3rd ed. Miami: Montgomery Scientific, 1985.

16) Scheartz Costea N: Autoimmune hemolytic anemia: clinical correlations and biological implications. Semin Hematol 1966; 3: 2-26.

17) Garratty G, Arndt P, Nance S, Postoway N: Low affinity autoantibodies-a cause of false negative direct antiglobulin tests. Joint Congress International Society of Blood Transfusion/American Association of Blood Banks, Book of Abstracts, 1990; 87.

18) van der Meulen FW, de Bruin HG, Goosen PCM et al: Quantitative aspects of the destruction of red cells sensitized with IgG1 autoantibodies: an application of flow cytometry. Br J Haematol 1980; 46: 37-56.

19) Hughes-Jones NC: The estimation of the concentration and equilibrium constant of anti-D. Immunol 1967; 12 : $567-71$.

20) Nance S, Garratty G: Correlates between in vivo hemolysis and the amount of RBC-bound IgG measured by flow cytofluorometry. Blood 1984; 64: 88a (abstract).

21) Garratty G, Nance S: Correlation between in vivo hemolysis and the amount of red cell bound IgG measured by flow cytometry. Transfusion 1990; 30: 617-21.

22) Gilliland BC, Baxter E, Evans RS: Red-cell antibodies in acquired hemolytic anemia with negative antiglobulin serum tests. N Engl J Med 1971; 285: 252-6.

23) Garratty G: Factors affecting the pathogenicity of red cell auto- and alloantibodies. In: Nance SJ, ed. Immune destruction of red blood cells. Arlington, VA: Ameroican Association of Blood Banks, 1989: 109-169.

24) Lachmann PJ, Voak D, Oldroyd RG, Downie DM, Bevan PC: Use of monoclonal anti-C3 antibodies to characterise the fragments of C3 that are found on erythrocytes. Vox Sang 1983; 45: 367-72.

25) Frank MM, Hamburger MI, Lawley TJ, Kimberly RP, Plotz PH: Defective reticuloendothelial system Fc-receptor function in systemic lupus erythematosus. N Eng J Med 1979; 300: 518-23.

26) Kelton JG: Impaired reticuloendothelial function in patients treated with methyldopa. N Engl J Med 1985; 313: $596-600$. 